\title{
BIOMECHANICAL ANALYSIS OF RUNNING GAIT CHARACTERISTICS OF BASKETBALL PLAYERS WITH ANKLE INJURY
}

\author{
Hailong Xia \\ Henan University of Engineering, Henan, 451191, China \\ E-mails: hailxhaue@126.com
}

\begin{abstract}
Ankle joint injury is a common kind of sports injury, which can severely affect athlete's career. In this study, we collected the gait feature data of basketball professional students during running and carried out a biomechanical analysis on the impact of ankle joint injury on gait characteristics and foot force distribution during running. It is found that ankle joint injury can lead to the relocation of the plantar centre of gravity, i.e., the occurrence of protective compensatory phenomenon. The plantar pressure analysis system can be used for early detection of changes in plantar pressure. As more and more people are involved in physical exercise, this study has application values in helping people to avoid ankle joint injuries.
\end{abstract}

Keywords: Knee joint, Gait characteristics, Running, Biomechanics.

\section{Introduction}

Ankle joint plays an important role in running and jumping [10].

The main symptoms of ankle sprain are part or complete tear of the ligament and periosteal stripping at the ligament attachment point [12] caused by ankle joint reverse sprain. Since some of the fibres of the ligament are involved in the composition of the joint capsule [15], ankle ligament injury may lead to joint capsule and joint synovial injury complications, as well as joint bleeding and swelling, etc. [6]. Many sports, especially gymnastics and basketball, often require athletes to do jumping actions, which increases the risk of ankle joint injuries on athletes. Running is critical to human health and exercise, and it helps prevent chronic diseases [2]. In order to maintain the health of athletes, it is of great significance to perform biomechanical assessment on the movement gait of athletes.

More importantly, the improvement of athlete's competitiveness is based on the good training and rehabilitation practice adhering to biomechanical principles [14]. In this paper, gait analysis is performed by collecting and analyzing biomechanical data. Gait analysis is a systematic study of human motion [9], during which physical movement, physical mechanics and muscle activity values are measured for analysis, which is often applied in sports biomechanics.

Biomechanical examination involves the measurement of lower limb movement [11], as well as assessment of joint movement, muscle strength and flexibility in athletes to help them move more efficiently and determine the posture-related or sport-related problems of the injured athletes [3], which can be applied in studies of injury prevention and treatment performance improvement.

\section{Materials and Methods}

Foot pressure can reflect the movement of the lower limbs of the human body while its changes can cause changes in the pressure on each lower limb joint [7].

If there are body or foot-related tissue lesions, the peak pressure of foot-related areas and its distribution will change, which happens earlier than the appearance of clinical symptoms and physical signs.

Therefore, the plantar pressure analysis can accurately determine the early occurrence of certain diseases, as well as predict their development and consequences and can reflect the force changes in some parts caused by lesions in other parts [1].

Therefore, plantar pressure analysis is extensively applied in biomechanical analysis. The relationship between plantar stress analysis and gait analysis mainly includes four factors: clinical analysis, kinematics analysis, dynamic analysis and dynamic electromyography analysis [13].

In this paper, biomechanics was used to analyze the gait characteristics of athletes with ankle joint injuries.

\section{Research objects}

Forty male basketball players were included from the College of Physical Education of Zhengzhou Normal University with stratified cluster sampling method and divided into a control group and an ankle injury group. 
Through the comparison between the two groups, the impact of sports injury on athlete's foot pressure and gait characteristics was studied.
Table 1 shows the information of the research objects.

Table 1: Basic information of athletes (M SD)

\begin{tabular}{|l|l|l|l|l|l|}
\hline Grouping & Number & Age & Height $(\mathrm{cm})$ & Weight $(\mathrm{kg})$ & $\begin{array}{l}\text { Years ox } \\
\text { exercise (year) }\end{array}$ \\
\hline Control group & 14 & $21.43 \pm 1.34$ & $186.94 \pm 6.87$ & $79.95 \pm 7.84$ & $5.95 \pm 1.79$ \\
\hline Injury group & 26 & $21.44 \pm 0.77$ & $188.36 \pm 6.59$ & $83.64 \pm 10.71$ & $7.99 \pm 1.86$ \\
\hline
\end{tabular}

\section{Testing equipment}

The Sweden Qualisys-MCU500 infrared spot test system is adopted in this study, which includes six high-speed cameras, infrared light spots and a data mining system, with data mining frequency set to $200 \mathrm{~Hz}$.

The three-dimensional gait analysis system is used to analyze gait, along with Footscan7 USB flatbed foot pressure test system. Sensors are placed by $4 / \mathrm{cm}^{2}$.

\section{Testing of movement stages}

Firstly, basketball players needed to do warm-up exercise for 5-15 minutes to avoid sports injuries. Running action standard is as follows: swing arm, with left and right swing range not exceeding the centre of the body. Keep the head and shoulder stable, with the waist naturally upright. Make the muscle slightly tense and maintain the trunk posture, with the feet placed about a foot in front of the body, near the centre line. Shuttle running once on the basketball field is taken as one test, with a uniform speed, which is carried out three times (with 15 minutes interval between two tests). Finally, a mean value is obtained.

\section{Research methods}

Literature research method: According to the research content and purpose of this paper, the author reviewed the relevant foreign literature on Chinese Academic Journal Full - text Database, China National Knowledge Internet, PubMed Central and Science Direct database using Google search function to better understand the research status quo in this field as well as lay the theoretical foundation for the study.

Experimental method: By collecting the data of gait cycle, step size, step length, pace, plantar pressure, landing and off-ground time and regional impulse, the plantar pressure distribution and gait characteristics of basketball players with ankle injury were studied.

Meanwhile, the effects of sports injuries on the foot pressure and gait characteristics of athletes were obtained through comparing the control group with the injury group.

\section{Statistical analysis}

SAS6.1.2 statistical analysis system is used to process data. The mean value and standard deviation of each variable are expressed as M SD.
It is considered that the differences have statistical significance when $\mathrm{p}<0.05$ and $\mathrm{p}<0.01$.

\section{Results}

Ankle sprain is a very common injury, from which about 25, 000 people suffer every day. A sprained ankle means that one or more ligaments on the outside of the ankle are stretched or torn, which can turn into a long time problem once not properly treated. Usually, ankle sprain can be divided into two kinds, i.e., inward reverse sprain and outward reverse sprain. Outward reverse sprain which causes ankle lateral pain is the most common type of ankle sprain [8]. Basketball requires athletes to constantly jump, changing the body posture, which is very likely to cause injuries, dislocation or even fracture. The type and degree of injury of the ankle joint of the basketball players are shown in Figure 1 and 2 .

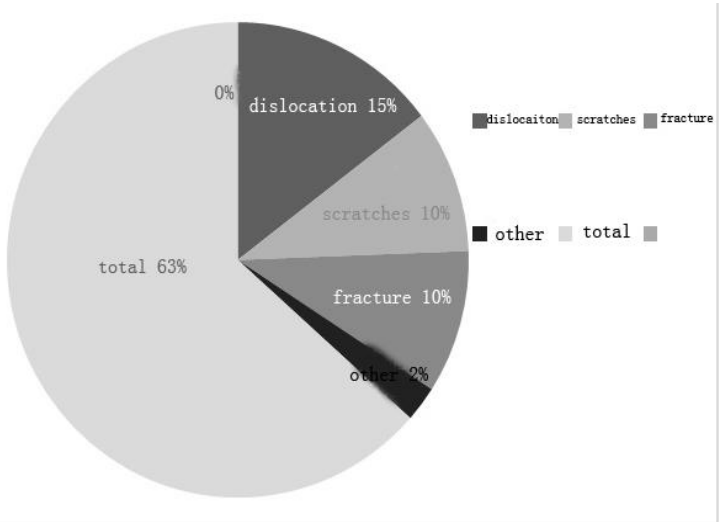

Figure 1: Ankle joint injury type

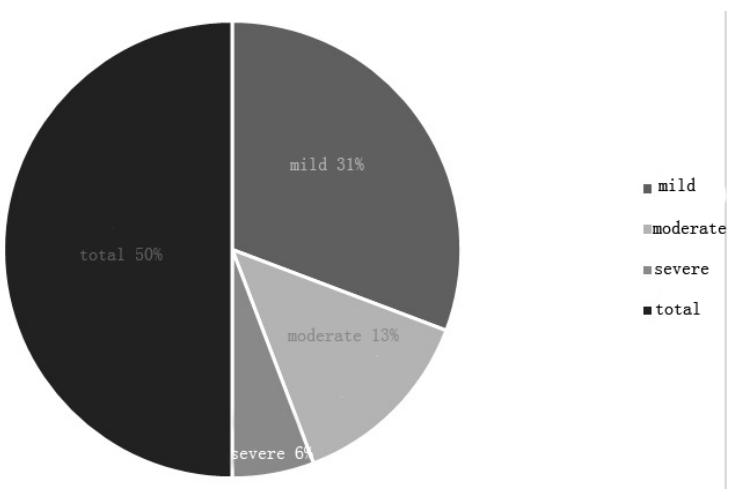

Figure 2: Ankle joint injury degree 


\section{Space-time parameter comparison}

Through the experimental test, two sets of time and space parameters are obtained (see Table 2).

Compared with the control group, the percentage of the support phase of the injury group was significantly decreased $(p<0.05)$ and the percentage of wobbling phase in the injury group was significantly increased $(\mathrm{p}<0.05)$.

Table 2 Comparison of time-space parameters between control group and injury group (M SD)

\begin{tabular}{|l|l|l|}
\hline Parameter & $\begin{array}{l}\text { Control group } \\
\mathrm{N}=14\end{array}$ & $\begin{array}{l}\text { Injury group } \\
\mathrm{N}=26\end{array}$ \\
\hline Gait cycle (s) & $1.12 \pm 0.03$ & $1.09 \pm 0.05$ \\
\hline $\begin{array}{l}\text { Percentage } \\
\text { of support } \\
\text { phase (\%) }\end{array}$ & $57.94 \pm 1.08$ & $57.61 \pm 0.91 \star$ \\
\hline $\begin{array}{l}\text { Percentage } \\
\text { of swing } \\
\text { phase (\%) }\end{array}$ & $41.03 \pm 1.08$ & $42.41 \pm 0.91 \star$ \\
\hline Step (m) & $0.81 \pm 0.03$ & $0.79 \pm 0.04$ \\
\hline $\begin{array}{l}\text { Step length } \\
\text { (m) }\end{array}$ & $1.52 \pm 0.17$ & $1.56 \pm 0.08$ \\
\hline Pace (m/s) & $2.13 \pm 0.04$ & $1.98 \pm 0.09$ \\
\hline Step / height & $0.44 \pm 0.02$ & $0.38 \pm 0.02$ \\
\hline $\begin{array}{l}\text { Step } \\
\text { length/heigh } \\
\text { t }\end{array}$ & $0.87 \pm 0.04$ & $0.82 \pm 0.05$ \\
\hline Pace/height & $0.80 \pm 0.04$ & $0.77 \pm 0.05$ \\
\hline $\begin{array}{l}\text { Ankle } \\
\text { sagittal } \\
\text { movement } \\
\text { range (mm }{ }^{2} \text { ) }\end{array}$ & $21.09 \pm 3.76$ & $20.49 \pm 2.37$ \\
\hline
\end{tabular}

Note: compared with the control group $\star \mathrm{P}<0.05$, $\star$ $\star \mathrm{P}<0.01$.

\section{Comparison of plantar pressure}

The foot can be divided into the following ten parts: Toe 1, Toe 2-5, Meta 1, Meta 2, Meta 3, Meta 4, Meta 5, Midfoot, Heel Med, and Heel Lat, as shown in figure 3.

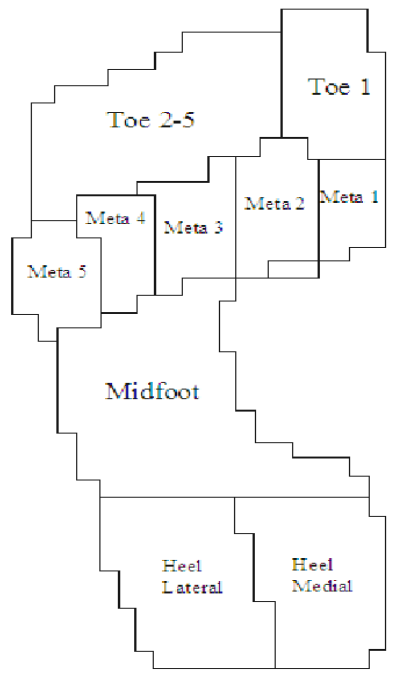

Figure 3: Schematic diagram of plantar pressure partition
Compared with the control group, the medial pressure in the injured group was decreased and the lateral pressure increased, with obvious changes in Toe 2-5 and Meta $3(\mathrm{p}<0.05)$ and significant changes in Meta 1, Meta 2, Meta 4 and Meta $5(\mathrm{p}<0.01)$, as shown in table 3.

Table 3 Comparison of the plantar pressure between the control group and the injury group $(\mathrm{N} / \mathrm{kg})$

\begin{tabular}{|l|l|l|}
\hline $\begin{array}{l}\text { Plantar } \\
\text { division }\end{array}$ & $\begin{array}{l}\text { Control group } \\
\mathrm{N}=14\end{array}$ & $\begin{array}{l}\text { Injury group } \\
\mathrm{N}=26\end{array}$ \\
\hline Toe 1 & $3.68 \pm 1.14$ & $3.08 \pm 1.12$ \\
\hline Toe $2-5$ & $0.65 \pm 0.41$ & $0.99 \pm 0.57 \star$ \\
\hline Meta 1 & $3.77 \pm 1.32$ & $1.89 \pm 0.95 \star \star$ \\
\hline Meta 2 & $5.04 \pm 1.21$ & $2.43 \pm 0.98 \star \star$ \\
\hline Meta 3 & $2.54 \pm 1.13$ & $3.74 \pm 1.08 \star$ \\
\hline Meta 4 & $1.59 \pm 0.42$ & $4.93 \pm 1.21 \star \star$ \\
\hline Meta 5 & $1.02 \pm 0.34$ & $4.21 \pm 1.39 \star \star$ \\
\hline Mid foot & $2.37 \pm 0.95$ & $3.44 \pm 1.27 \star$ \\
\hline $\begin{array}{l}\text { Heel } \\
\text { Medial }\end{array}$ & $5.03 \pm 1.39$ & $4.28 \pm 1.25$ \\
\hline $\begin{array}{l}\text { Heel } \\
\text { Lateral }\end{array}$ & $4.57 \pm 1.36$ & $4.95 \pm 1.03$ \\
\hline
\end{tabular}

Note: compared with the control group $\star \mathrm{P}<0.05, \star$ $\star \mathrm{P}<0.01$.

As shown in figure 4, compared with the control group, the foot pressure center of the injured group was significantly shifted to the lateral side, with Meta 4 and Meta 5 pressure increased significantly and Toe, Meta 2 and Meta 1 pressure decreased.
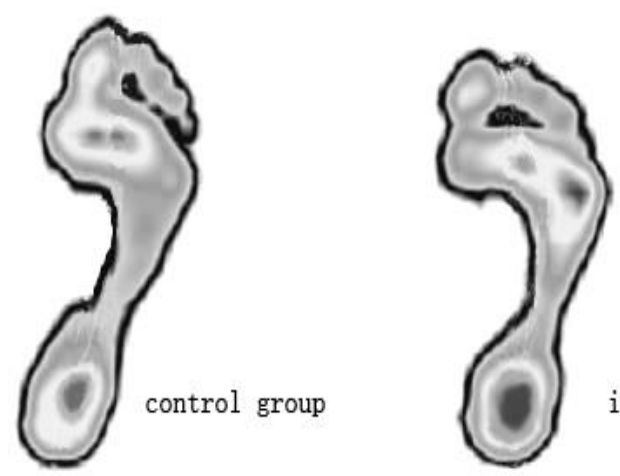

injury group

Figure 4: trajectories of the plantar centre of gravity

Comparison between landing time and off-ground time

As shown in table 4 and 5 , there was no significant difference between the two groups in the landing time and the off-ground time, suggesting that these minor differences should not be associated with ankle injury. 
Table 4 Comparison of percentage of landing time (M SD)

\begin{tabular}{|l|l|l|}
\hline $\begin{array}{l}\text { Plantar } \\
\text { division }\end{array}$ & $\begin{array}{l}\text { Control group } \\
\mathrm{N}=14\end{array}$ & $\begin{array}{l}\text { Injury group } \\
\mathrm{N}=26\end{array}$ \\
\hline Meta 1 & $8.31 \pm 4.27$ & $7.89 \pm 4.38$ \\
\hline Meta 2 & $5.74 \pm 2.87$ & $5.96 \pm 2.48$ \\
\hline Meta 3 & $4.39 \pm 2.21$ & $4.61 \pm 2.13$ \\
\hline Meta 4 & $3.88 \pm 2.05$ & $4.02 \pm 2.39$ \\
\hline Meta 5 & $4.51 \pm 2.17$ & $5.14 \pm 3.08$ \\
\hline
\end{tabular}

Table 5 Comparison of percentage of off-ground time (MSD)

\begin{tabular}{|l|l|l|}
\hline $\begin{array}{l}\text { Plantar } \\
\text { division }\end{array}$ & $\begin{array}{l}\text { Control group } \\
\mathrm{N}=14\end{array}$ & $\begin{array}{l}\text { Injury group } \\
\mathrm{N}=26\end{array}$ \\
\hline Meta 1 & $95.32 \pm 2.08$ & $95.61 \pm 1.89$ \\
\hline Meta 2 & $95.33 \pm 2.13$ & $95.49 \pm 2.05$ \\
\hline Meta 3 & $93.68 \pm 1.97$ & $95.09 \pm 2.14$ \\
\hline Meta 4 & $92.17 \pm 1.61$ & $93.58 \pm 2.07$ \\
\hline Meta 5 & $87.14 \pm 3.59$ & $89.01 \pm 2.71$ \\
\hline
\end{tabular}

\section{Comparison of percentage of impulse}

As shown in table 6, compared with the control group, the percentage of impulse in the second metatarsal region of the injury group decreased $(p$ $<0.05)$ while that in the fourth metatarsal region increased $(\mathrm{p}<0.05)$.

Table 6 Comparison of percentage of impulse (M SD)

\begin{tabular}{|l|l|l|}
\hline $\begin{array}{l}\text { Plantar } \\
\text { division }\end{array}$ & $\begin{array}{l}\text { Control group } \\
\mathrm{N}=14\end{array}$ & $\begin{array}{l}\text { Injury group } \\
\mathrm{N}=26\end{array}$ \\
\hline Med heel & $53.47 \pm 4.89$ & $51.34 \pm 3.36$ \\
\hline Lat heel & $46.85 \pm 4.89$ & $48.51 \pm 3.36$ \\
\hline Meta 1 & $22.04 \pm 4.17$ & $20.75 \pm 6.42$ \\
\hline Meta 2 & $27.08 \pm 1.33$ & $25.24 \pm 3.67 \star$ \\
\hline Meta 3 & $23.37 \pm 2.47$ & $22.08 \pm 2.49$ \\
\hline Meta 4 & $19.25 \pm 2.99$ & $22.14 \pm 4.17 \star$ \\
\hline Meta 5 & $7.84 \pm 4.23$ & $10.08 \pm 4.61$ \\
\hline
\end{tabular}

Note: compared with the control group $\star \mathrm{P}<0.05$, $\star \mathrm{P}<0.01$.

\section{Result Analysis}

Through testing, it is found that the percentage of the support phase of the injury group was significantly larger, which is inferred to be due to that basketball players with ankle injury can reduce the load on the injured ankle joint by weight conversion through shifting the center of gravity of the body; there was no significant difference in pace between the two groups.

As shown in the foot pressure center of gravity trajectory, compared to the control group, there was a significant difference between the 3rd metatarsal and the 2-5 toe area in the injury group.
Besides, the first metatarsal and second metatarsal pressure decreased while the fourth metatarsal and fifth metatarsal pressure increased. In addition, the highest peak of plantar pressure appeared in the fourth metatarsal, which is significantly different from the control group.

Generally, the trajectories of the center of gravity of the injured group were shifted outward, with the inner peak decreased and the outer peak increased, which is considered to be the protective compensatory phenomenon. Due to training, the adaptability of the foot pressure of the control group changed, resulting in the increase of inner pressure over the outer pressure. Besides, the increase in the outer pressure and decrease in the inner pressure of the injury group may be the adaptability changes of the body to reduce the load and pain caused by injury.

\section{Conclusion}

As shown in the experimental results, the injury group was significantly smaller than the control group in the peak pressure index. There was significant difference between the two groups in the second to fifth toe regions, and the injury group was larger than the control group.

The reason for the greater peak pressure value of the injury group may be that the center of gravity of the body is biased towards the normal foot so that the injured one suffers less body quality and less pressure [5]. It is such a protective compensation mechanism of the human body that causes local plantar pressure changes. The plantar pressure analysis system can help find early plantar pressure changes, so as to achieve early problem detection, analyze the causes and avoid unnecessary physical lesions. Ligament injury requires rehabilitation training, which therefore is inevitable for basketball players who are prone to ligament injuries. If the damaged ankle cannot be completely healed, the player is likely to be injured again. Ankle joint injury recovery generally covers three stages [4]: stage 1 : rest and reduce the swelling of the injured ankle; stage 2: restore ankle flexibility and strength; stage 3: resume exercise and carry out maintenance exercises to gradually strengthen the damaged muscles and ligaments. If not completely recovered, sequelae such as chronic pain and arthritis may occur [16].

Due to the limitation of the conditions, the number of samples chosen in this paper is very limited. In the future research, it is expected to expand the sample range and increase the number of samples in order to make the experimental results more accurate. 


\section{References}

[1] Bai Y L, Liu J. (2012). Sports Injury of World Excellent Basketball Players Viewed from Epidemiology. Journal of Sports Adult Education, 59-71.

[2] Cosby N L, Hertel J. (2011). Clinical assessment of ankle injury outcomes: case scenario using the foot and ankle ability measure. Journal of Sport Rehabilitation, 20(1):89-99.

[3] D. Mandeville, L. R. Ostemig, L. S. Chou. (2008). The effect of total knee replacement surgely on gait stability. Gait Posture, Vol.27 (1): 103-109.

[4] Digiovanni B F, Partal G, Baumhauer J F. (2004). Acute ankle injury and chronic lateral instability in the athlete. Clinics in Sports Medicine, 23(1):119.

[5] Fong T P, Hong Y, Chan L K, et al. (2007). A Systematic Review on Ankle Injury and Ankle Sprain in Sports. Sports Medicine, 37(1):73-94.

[6] Fujii T, Kitaoka H B, Watanabe K, et al. (2006). Comparison of modified Broström and Evans procedures in simulated lateral ankle injury. Medicine \& Science in Sports \& Exercise, 38(6):1025-31.

[7] Hessert MJ, Vyas M, Leach J, et al. (2005). Foot pressure distribution during walking in young and oldadults. BMC Geriatrics, 5(1):8.

[8] Hirose K, Murakami G, Minowa T, et al. (2004). Lateral ligament injury of the ankle and associated articular cartilage degeneration in the talocrural joint: anatomic study using elderly cadavers. Journal of Orthopaedic Science Official
Journal of the Japanese Orthopaedic Association, 9(1):37-43.

[9] Margetić P, Pavić R. (2012). Comparative assessment of the acute ankle injury by ultrasound and magnetic resonance. Collegium Antropologicum, 36(2):605.

[10] Mckay G D, Goldie P A, Payne W R, et al. (2001). Ankle injuries in basketball: injury rate and risk factors. British Journal of Sports Medicine, 35(2):103.

[11] M. Berchuck, T.P. Andriacchi, B.R. Bachel al. (1990). Gait adaptations by patients who have a deficient anterior cruciate ligament. J Bone Joint Surg Am, Vol.72 (6): 871-877.

[12] Nordin M, Frankel V H. (2001). Basic biomechanics of the musculoskele-tal system. Baltimore MD: Lippincott Williams and Wilkins, 25-37.

[13] Ralf D. Linke, hilip B. Schoettle, Andreas B. Imhoff. (2002). SPORTVERLETZUNGEN IM KINDES-UND JUGENDALTER: Der "Snowboarders' ankle" - Ätiologie, Diagnostik, Therapie. Sport-Orthopädie - SportTraumatologie, 18(3):177-180.

[14] R. Ferber, L.R. Osternig, M.H. Woollacolt et al. (2002). Gait mechanics in chronic ACL deficiency and subsequent repair. Clin Biomech (Bristol. Avon), Vol.17 (4): 274-285.

[15] Whittle M W. (2007). An introduction to gait analysis. Boule-vard, PA: Elsevier, 114-125.

[16] Ying Liu, Hui Yue. (2017). Quantitative Simulation of Damage Roots on Inoculated Alfalfa by Arbuscular Mycorrhiza Fungi. Int. J. Bioautomation, 21(4):317-324.

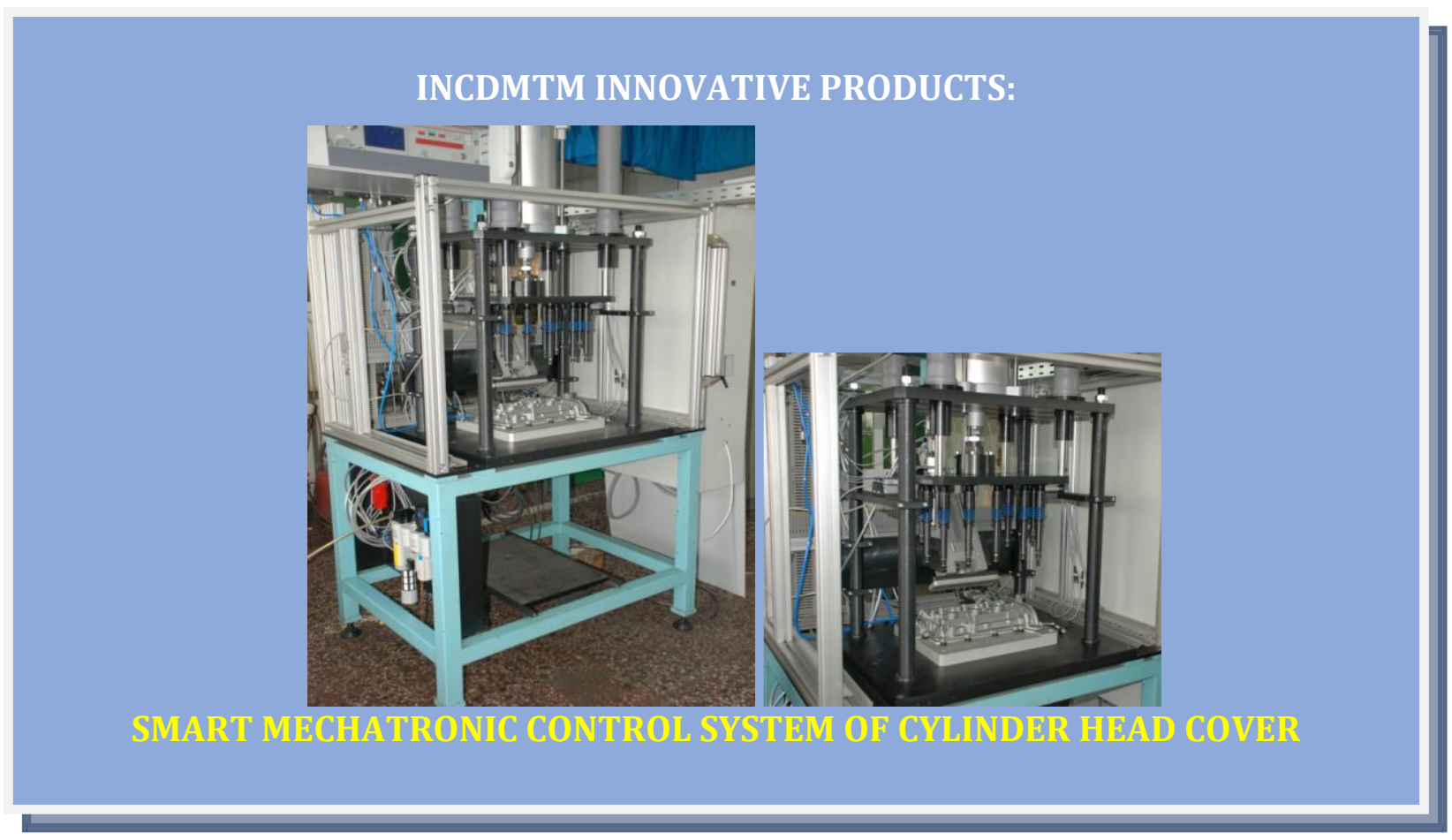

